\title{
PERKEMBANGAN MUTAKHIR DALAM PENELITIAN \\ INTERVENSI \\ UNTUK KEPRIBADIAN AMBANG
}

\author{
Christine Wibhowo
}

\begin{abstract}
ABSTRAK
Orang dengan kepribadian ambang (ODKA) menurut DSM-IV, biasanya dimulai sejak dewasa awal dan ditunjukkan dengan kriteria antara lain gangguan identitas, impulsif, perasaan kosong dan ada keinginan untuk bunuh diri. Orang dengan KA jika tidak segera diintervensi dikuatirkan akan membahayakan dirinya sendiri dan orang di sekitarnya. Oleh karena itu artikel ini dimaksudkan untuk melihat intervensi-intervensi mutkahir yang telah dilakukan guna mengetahui keefektifan dari intervensi tersebut.Hasilnya adalah karena kepribadian ambang menyentuh aspek kognitif, afeksi dan interpersonal dan penyebabnya juga bisa karena aspek beurobiologi, trauma masa anak dan kehidupan saat dewasa, maka intervensi juga dilakukan dengan berbagai pendekatan.Pendekatan yang digunakan adalah psikodinamik, kognitif, perilaku dan farmokologi.Tidak ada satu terapi yang ditemukan lebih efektif dibanding terapi lainnya. Dengan kata lain intervensi akan sesuai jika dipilih berdasar penyebab dan gejala yang paling menonjol dari ODKA.
\end{abstract}

Kata Kunci: kepribadian ambang, intervensi mutakhir, psikodinamik,perilaku,kognitif

LATAR

BELAKANG

\section{MASALAH}

Borderline personality di dalam semua literatur psikologi dan PPDG (Pedoman Penggolongan Diagnosis Gangguan Jiwa) diterjemahkan sebagai kepribadian ambang (KA).Penelitian tentang KA telah banyak dilakukan di negaranegara Barat namun masih sedikit dilakukan di negara Timur.Demikian juga penelitian tentang KA di Indonesia juga 
masih belum banyak dilakukan.Kalaupun ada, maka biasanya penelitian tersebut dlakukan oleh para peneliti dari bidang kedokteran.Penelitian dari Kusumawardhani (2007) menemukan bahwa memang ada faktor di bagian otak (prefrontal korteks) yang memengaruhi terjadinya KA.Ia menjelaskan bahwa neurotransmiter, genetik dan neuroendokrin menjadi penyebab seseorang mengalami KA.

Walaupun belum mendapat perhatian yang cukup, akan tetapi kepribadian ambang ini adalah suatu gangguan yang definisinya diterima oleh para profesional kesehatan di dunia. (Wong, 2012). Mereka juga menemukan bahwa walau KA awalnya tidak menampakkan gejala yang menonjol seperti gangguan depresi, namun jika dibiarkan akan sangat membahayakan karena orang dengan KA (ODKA) akan mencelakai diri sendiri dan orang lain. Kurang menonjolnya ciri dari KA inilah yang penulis duga sebagai salah satu penyebab kurangnya penelitian tentang KA di Indonesia.

Nevid (2005) menuliskan bahwa banyak tokoh psikologi yang mencoba menganalisa penyebab terjadinya KA. Seorang tokoh bernama Kernberg menyatakan bahwa KA sangat terkait dengan kegagalan di masa pra-oedipal saat anak harus membuat sintesa antara citra diri dan citra orang lain. Anak merasa bahwa ia atau orang lain secara total baik dan secara total buruk. Perasaan ini akan membuat ia mengalami splitting saat berinteraksi dengan orang lain. Splitting inti termasuk dalam ciri KA yang menonjol. Orang dengan splittingakan mengalami benci dan rindu secara cepat dan menyebabkannya bingung dalam mengambil keputusan.Kegagalan di masa pre-odipal disebabkan oleh hubungan orangtua dan anak yang tidak hangat.Perceraian orangtua dan kekerasan yang 
dialami di masa anak-anak adalah juga menjadi penyebabnya.

Mirip dengan yang dikemukakan oleh Kerberg, tokoh lain dalam tulisan Nevid adalah Margaret Mahler yang menyatakan bahwa KA sangat terkait dengan figure ibu di masa anak-anak berusia dini.Kegagalan anak untuk memisahkan diri dari subjek lekat (ibu) merupakan awal terjadinya KA. Kegagalan anak memiliki identitas diri disebabkan karena peran ibu yang tidak konstan.Anak menjadi tidak aman.

Lebih lanjut adalah berdasar perspektif keluarga (Nevid,2005) yang berpendapat bahwa KA sangat dipengaruhi oleh hubungan dalam keluarga. Orang dengan KA biasanya mengenang orangtuanya sebagai orang yang lebih mengontrol namun tidak peduli dengan anak. Gangguan kepribadian lain memang juga dipengaruhi oleh pengalam masa kanak-kanak dengan keluarga akan tetapi hubungan keluarga yang dingin lebih kuat dalam menyebabkan KA dibanding gangguan lain. Orang dengan KA menggambarkan orang-orang di masa kecilnya adalah orang yang kejam, jahat, sengaja melukainya dan gagal menolong saat dirinya disakiti. Orang dengan gangguan yang lain tidak merasakan hal tersebut secara spesifik.

Dengan beberapa pandangan mengenai penyebab $\mathrm{KA}$, maka banyak pula intervensi mutakhir yang dilakukan untuk menghambat terjadinya KA. Beberapa intervensi mutakhir tersebut akan diulas dalam artikel ini.

\section{TINJAUAN PUSTAKA}

Menurut The International Classification of Diseases, 10th edition atau ICD-10 (dalam Caihol, et. al; 2012) bahwa ODKA (orang dengan kepribadian ambang) memiliki gangguan di beberapa dimensi, yaitu : 


\begin{tabular}{l|l}
\hline KRITERIA DSM & DIMENSI \\
$\begin{array}{l}\text { Afeksi tidak stabil } \\
\begin{array}{l}\text { Perasaan kosong kronis } \\
\text { Marah tidak terkontrol }\end{array}\end{array}$ \\
$\begin{array}{l}\text { Gangguan identitas } \\
\text { Paranois, stress, disosiasi }\end{array}$ & KOGNISI \\
$\begin{array}{l}\text { Seks, ketagihan } \\
\text { Kcinginan burnuh diri }\end{array}$ & IMPULSIF \\
$\begin{array}{l}\text { Cemas berlebihan untuk } \\
\text { ditinggal } \\
\text { Hubungan tak stabil }\end{array}$ & INTERPERSONAL
\end{tabular}

Oleh karena itu, maka muncullah beberapa intervensi untuk membantu mengurangi KA.Intervensi tersebut muncul berdasar teori medis, psikoanalisa dan perilaku atau kognitif.

\section{Farmakologi}

Intervensi dengan obat ini didasari pemikiran bahwa ODKA memiliki profil neurobiologi yang unik(Oldham,Gabbard,201 0; Andri, \& Kusumawardhani, A;2007). Pada bagian profrontal korteks mengalami gangguan yang menyebabkan ODKA kesulitan dalam mengambil keputusan dan impulsif.
Obat dengan jenis SSRI (Selektive serotonin reuptake inhibitor)telah terbukti dapat mengurangi perilaku agresif (verbal) dan mengurangi suara afektif

2. Eye Movement

Desensitization and Reprocessing (EMDR)

EMDR ini menggunakan pendekatan neurobiology (Brown,Saphiro;2006).

EMDR efektif untuk menolong ODKA dalam menghilangkan penyebab KA yaitu perasaan diabaikan atau trauma di masa anak.

Tujuan dari EMDR ini adalah mengingat kembali peristiwa masa lalu maladaptif dan mengenal situasi masa kini yang menimbulkan distress.Dengan menyadari adanya pengalaman tersebut diharapkan terjadinya disensitisasi 
(tidak lagi sensitif dengan perasaan sakit). Perasaan yang lepas dari luka akan membuat ODKA lebih bisa memandang masa depan.

Secara singkat, cara kerja EMDR adalah mengajak ODKA mengingat masa lalu yang sedih dengan diberi stimulus eksternal (gerakan jari). Kemudian ODKA diminta mengikuti gerakan jari.Gerakan mata yang cepat dari ODKA dalam EMDR menciptakan aktivitas otak yang mirip dengan REM (rapid eye movement).REM ini membantu dalam pengolahan ide dan menyelesaikan konflik.Sehingga membuat memori menjadi tak menyakitkan.

3. Dialektical Behaviour Therapy (DBT) DBT ini dikenalkan oleh Marsha Linehan. Dasar pemikiran dari intervensi ini adalah pendekatan kognitif-perilaku yang menekankan aspek psikososial. Intervensi ini memusatkan perhatian pada adanya dukungan dan bukan kemampuan kognitif yang sempurna. Inti dari DBT adalah regulasi emosi, toleran pada distress dan meningkatkan efektivitas dalam menjalin hubungan interpersonal (Verheul, Den Bosch, 2003)

4. Schema Therapy Terapi ini mendasarkan pada pendekatan gestalt yang mengutamakan hubungan baik antara terapis-klien. ST sesuai untuk mengatasi truma masa anak, mengajak ODKA melakukan reparenting dan menyediakan pendampingan kehidupan sehari-hari.Pendampingan menjadi sangat penting karena seringkali ODKA 
baik saat mengikuti sesi terapi namun kesulitan ketika menghadapi kenyataan (Kellog and Young, 2016).

5. System Training for Emotional Predictability and Problem Solving (STEPPS)

Menurut Quinn (2011) inti dari terapi ini adalah mengajak ODKA untuk menyadari gangguannya dan bisa mengantisipasi jika ada peristiwa yang membuatnya tidak stabil.Terapi ini juga mendukung agar ODKA lebih percaya diri menghadapi persoalan. STEPPS termasuk dalam terapi yang beraliran perilaku

6. Transference-Focused psychotherapy (TFP) Dari beberapa terapi yang telah disampaikan sebelumnya, maka TFP termasuk dalam terapi andalan walau bukan berarti satu-satunya terapi terbaik.

TFP mendasarkan pada pandangan psikodinamik. Terapi yang diajukan oleh Kernberg (Levy,Clarkin,Scott,Kernb erg, 2006) ini bertujuan untuk membuat hal-hal yang berada di bawah sadar menjadi disadari, meningkatkan toleransi dan menunda tindakan impulsif. Selain itu TFP juga bertujuan untuk mengembangkan fungsi reflektif , mendukung ODKA untuk lebih paham motivasi internal diri dan orang lain. Dengan demikian maka TFP akan membantu ODKA untuk mengintegrasikan aspekaspek dalam diri sendiri dan orang lain.

Selanjutnya TFP juga mengajarkan cara coping yang tepat. Hubungan baik 
dengan terapis menjadi dasar dalam TFP ini karena hubungan baik adalah sarana untuk ODKA bertumbuh.

Tahapan dalam TFP adalah interpretasi tentang duduk permasalahan, konfrontasi, klarifikasi, elaborasi dan empati dari terapis.

\section{METODE PENGUMPULAN} DATA

$$
\begin{aligned}
& \text { Artikel-artikel tentang } \\
& \text { intervensi mutakhir yang dipakai } \\
& \text { dalam artikel ini adalah mulai } \\
& \text { tahun } 2000 \text { dan setelahnya.Akan } \\
& \text { tetapi jika ada yang di luar tahun } \\
& \text { tersebut namun masih cukup } \\
& \text { sesuai dengan keadaan saat ini, } \\
& \text { maka tetap digunakan untuk } \\
& \text { memperkaya analisa. } \\
& \text { Kata kunci dalam mencari } \\
& \text { artikel intervensi adalah intervensi } \\
& \text { dan kepribadian ambang.Jika } \\
& \text { diperhatikan maka tidak ada } \\
& \text { intervensi yang sama sekali baru } \\
& \text { namun intervensi tersebut } \\
& \text { dimodifikasi agar lebih tepat }
\end{aligned}
$$

untuk orang dengan kepribadian ambang.

\section{HASIL PENELUSURAN}

\section{LITERATUR}

Banyak artikel tentang intervensi buat ODKA. Tabel pada halaman 6-10akan ditunjukkan beberapa dari intervensi mutakhir yang memang dikhususkan untuk membantu ODKA menurunkan gejalanya.

\section{PEMBAHASAN}

Seperti telah dijelaskan di bagian teori, yaitu bahwa ODKA akan mengalami gangguan di bagian emosi, kognisi, interpersonal dan impulsif, maka intervensi yang dilakukan memang harus menyeluruh. Dengan kata lain harus bisa mengintervensi semua aspek tersebut.

Belum lagi jika melihat dari penyebab KA,maka selain terapinya yang bersifat menyeluruh, maka terapisnya juga tidak bisa bekerja sendiri dan harus bekerja dengan bidang lain. Seperti diketahui bahwa penyebab 
KA adalah selain karena faktor trauma masa kecil juga karena dipengaruhi oleh cara menghadapi persoalan di masa kini ditambah dengan adanya gangguan pada fungsi otak. Dengan demikian maka terapi untuk ODKA harus holistik, yaitu meliputu farmakologi, psikoterapi dan terapi perilaku.

Sampai saat ini belum ada intervensi yang dinyatakan sebagai intervensi yang paling jitu tetapi semua pendekatan (psikoanalisa, perilaku, farmakologi, meditasi) dapat digunakan untuk membantu ODKA. Agar intervensi tidak terlalu berat dan memakan waktu, maka psikolog bisa memilih intervensi yang paling tepat untuk ODKA sesuai dengan ciri yang menonjol. Jika menemui ODKA dengan ciri menonjol adalah luka akan masa lalu, maka bisa digunakan terapi yang beraliran psikoanalisa. Untuk ODKA yang dominan karena penyebabnya adalah gangguan otak, maka farmkoterapi akan lebih tepat untuk dipilih. Sedangkan ODKA dengan fobia sosial yang menonjol, maka lebih tepat digunakan intervensi dengan aliran behavior/perilaku.

\section{KESIMPULAN}

Intervensi dengan dasar psikoanalisa, perilaku, kognitif dan farmakologi tepat digunakan untuk membantu ODKA. Belum ada bukti yang menunjukkan bahwa hanya satu terapi yang lebih baik dari yang lain. Pendekatan secara menyeluruh memang baik digunakan agar semua aspek mendapat intervensi, namun bisa juga psikolog memilih satu terapi yang paling sesuai dengan ciri-ciri dari ODKA.Hal ini karena tiap terapi memiliki kelebihan yang unik.

\section{DAFTAR PUSTAKA}

Kusumawardhani, A. (2007). Neurobiologi Gangguan Kepribadian Ambang: Pendekatan Biologis Perilaku Impulsif dan Agresif. Maj Kedokt Indon, 57, 124-128. 
Bellino S1, Rinaldi C, Bozzatello P, Bogetto F. (2011) Pharmacotherapy of borderline personality disorder: a systematic review for publication purpose. Journal of Curr Med Chem. 2011;18(22):3322-9.

Brown, S., \& Shapiro, F. (2006). EMDR in the Treatment of Borderline Personality Disorder. Clinical Case Studies, 5, 403-420.

Caihol, Lionel; Gicquel, Ludovic \& Raynaldy, Jean-Philippe Raynaud; 2012; Borderline Personaity Disorder : IACAPAP Textbook of Child and Adolescent Mental Health

Chafos, V. H., \& Economou, P. (2014). Beyond Borderline Personality Disorder: The Mindful Brain. Social Work, 59, 297-302.

Clarkin, J. F., Levy, K. N., Lenzenweger, M. F., \& Kernberg, O. F. (2007). Evaluating Three Treatments for Borderline Personality Disorder: A Multiwave Study. Am $\boldsymbol{J}$ Psychiatry, 164, 922-928.

Cottraux,J.,Note,I.D, F., et al. (2009). Psychotherapy and Psychosomatic Borderline Personality Disorder. Evidence-based psychological

Interventions in The Treatment of Mental Disorders: A Literature
Review. The Australian Psychological sosiety

Eijk, C. V. (2014). Meta-Analysis of Mentalization Based Treatment (MBT) and Schema Focused Therapy for Borderline Personality Disorder: What Works for Whom? Meta-Analysis Borderline Personality Disorder , 1-23.

Fonagy, P., \& Bateman, A. W. (2007). Mentalizing and Borderline Personality Disorder. Journal of Mental Health, 16, 83101.

Glick, Ira,D., Dulit, Rebecca,A., Clarkin, Jhon F., (1995). The Family, Family Therapy, and Borderline Personality Disorder. Journal of Psychotherapy Pract Res. 1995 Summer; 4(3): 237-246.

Hagen, S., Woods-Giscombe, C. L., Chung, J., \& Beeber, L. S. (2014). Potential Benefits of Dialectical Behavioral Therapy for Adolescents Receiving Treatment for Borderline Personality Disorder Traits: Implications for Psychiatric Nurses. Nursing and Health, 2, 89-99.

Hoffman, P. D., Fruzzetti, A. E., \& Buteau, E. (2007). Understanding and engaging families: An Education, Skills and Support Program for 
relatives impacted by Borderline Personality Disorder. Journal of Mental Health, 16, 69-82. Kellog, S., \& Young, J. (2006). Schema Therapy for Borderline Personality Disorder. Journal of Clinical Psychology, 62, 445-458.

Kellogg, S. H., \& Young, J. E. (2006). Schema Therapy for Borderline Personality Disorder. Journal of Clinical Psychology, 62, 445-458.

Kernberg, O. F., Yeomans, F. E., Clarkin, J. F., \& Levy, K. N. (2008). Transference Focused Psychotherapy: Overview and Update. Int J Psychoanal, 89, 601620.

Leichsenring F, Salzer S, Beutel ME, Het.al. (2013). Psychodynamic therapy and cognitive-behavioral therapy in social anxiety disorder: a multicenter randomized controlled trial. American Journal of Psychiatry. 2013 Jul;170(7):759-67

Levy, K. N., Clarkin, J. F., Yeomans, F. E., Scott, L. N., Wasserman, R. H., \& Kernberg, O. F. (2006). The Mechanism of Change in the Treatment of Borderline Personality Disorder with Transference Focused Therapy. Journal of Clinical Psychology, 62, 481-501.

Levy, K. N., Meehan, K. B., Kelly, K. M., Clarkin, J. F., Kernberg, O. F., \& Weber, M. (2006, September 18). Change in Attachment Patterns and Reflective Function in a Randomized Control Trial of Transference-Focused Psychotherapy for Borderline Personality Disorder. Journal of Consulting and Clinical Psychology, 1027-1040.

Lynch, T.R,Trost,W.T., Salsman,N \& Linehan, M.M (2007). Dialectical Behaviour Therapy for Borderline Personality Disorder. Evidence-based psychological

Interventions in The Treatment of Mental Disorders: A Literature Review. The Australian Psychological sosiety

McMain, S., Korman, L. M., \& Dimeff, L. (2001). Dialectical Behavior Therapy and The Treatment of Emotion Dysregulation. In Session: Psychoterapy in Practice, 57, 183-196.

Miller, C. R., Eisner, W., \& Allport, C. (1994). Creative Coping: A Cognitive-Behavioral Group for Borderline Personality Disorde. 
Archives of Psychiatric Nursing, VIII, 280-285.

Nevid, Jeffrey S. Rathus,Spencer. Greene,Beverly. 2002. Psikologi Abnormal. Diterjemahkan oleh Tim Fakultas Psikologi UI. Jakarta : Erlangga

Oldham, J. M., Gabbard, G. O., Goin, M. K., Gunderson, J., Soloff, P., Spiegel, D., et al. (2010). Practice Guideline for Treatmen of Patiens with Borderline Personality Disorder. APA Practice Guidelines , 1-55.

Presius, K.-I., Kaver, A., Ekdahl, S., Asberg, M., \& Samuelsson, M. (2007). Stress and burnout in psychiatric professionals starting to use dialectical behavioural therapy on young self-harming women showing borderline personality symptoms. Journal of Psychiatric and Mental Health Nursing, 14, 635-643.

Quinn, A. (2011). A Person Center Approach to the Treatment of Borderline Personality Disorder. Journal of Humanistic Psychology, 51, 465.

Verheul, R., Van Den Bosch, L. M., Koeter, M. W., De Ridder, M. A., Stijnen, T., \& Van Den Brink, W. (2003). Dialectical Behaviour Therapy for Women with Borderline Personality Disorder.
British Journal of Psychiatry, 182, 135-140. Westen, D. (1991). CognitiveBehavioural Interventions in the Psychoanalytic Psychotherapy of Borderline Personality Disorder. Clinical Psychology Review, 11, 211-230.

Wong, Eugene Kee Onn, 2012. Boderline Personality Disorder in the East. Asian Journal of Psychiatry. 6 (1) : 80-81

Zanarini, Mary C., Frankenburg, Frances, (2008). A Preliminary, Randomized Trial of Psychoeducation for Women With Borderline Personality Disorder. Journal of Personality Disorders: Vol. 22, No. 3, pp. 284290.

Zavala, S. S., Bentley, K. H., \& Wilner, J. G. (2015). Transdiagnostic Treatment of Borderline Personality Disorder and Comorbid Disorders: A Clinical Replication Series. Journal of Psychology Disorders, 29, 1-17. 


\begin{tabular}{|c|c|c|c|c|c|c|}
\hline NO & TAHUN & PENELITI & JUDUL & $\begin{array}{c}\text { TERAPI/KATA } \\
\text { KUNCI }\end{array}$ & SESI & \\
\hline 1. & 2016 & $\begin{array}{l}\text { Lynch, } \\
\text { T.R,Trost,W.T., } \\
\text { Salsman,N }\end{array}$ & BPD & $\begin{array}{l}\text { Telephone } \\
\text { Consultation }\end{array}$ & & $\begin{array}{l}\text { Sangat membantu } \\
\text { ODKA di luar sesi } \\
\text { konseling, pada saat } \\
\text { mengalami masa krisis. }\end{array}$ \\
\hline 2. & 2015 & $\begin{array}{l}\text { (Zavala, Bentley, \& } \\
\text { Wilner, 2015) }\end{array}$ & $\begin{array}{l}\text { Trans diagnostic } \\
\text { Treatment of BPD } \\
\text { and Comorbid } \\
\text { Disorders }\end{array}$ & $\begin{array}{l}\text { Trans diagnostic } \\
\text { Treatment }\end{array}$ & & $\begin{array}{l}\text { a) Menurunkan } \\
\text { kecemasan dan depresi } \\
\text { b) Meningkatkan } \\
\text { kemamapuan regualsi } \\
\text { emosi }\end{array}$ \\
\hline 3. & 2014 & $\begin{array}{l}\text { (Chafos \& Economou, } \\
\text { 2014) }\end{array}$ & $\begin{array}{l}\text { Beyond BPD : The } \\
\text { Mindful Brain }\end{array}$ & $\begin{array}{l}\text { Peningkatan gray } \\
\text { matter dengan } \\
\text { meditasi }\end{array}$ & & $\begin{array}{l}\text { Mengurangi impulsive, } \\
\text { meningkatkanregulasiem } \\
\text { osi, } \\
\text { meningkatkanatensi,foku } \\
\text { sdanmencegahpenurunan } \\
\text { fungsikognitif }\end{array}$ \\
\hline 4. & 2014 & (Eijk, 2014) & $\begin{array}{l}\text { Meta Analysis of } \\
\text { Mentalization } \\
\text { Based Treatment } \\
\text { (MBT) and } \\
\text { Schema Focused } \\
\text { Therapy for BPD }\end{array}$ & $\begin{array}{l}\text { MBT } \\
\text { SFT }\end{array}$ & $\begin{array}{l}\text { 1x seminggu } \\
\text { dengan psiko } \\
\text { terapis } \\
3 \mathrm{x} \text { seminggu } \\
\text { dengan grup } \\
\text { terapis } \\
\text { 1x seminggu } \\
\text { psikodrama }\end{array}$ & $\begin{array}{l}\text { a) Psikodinamika } \\
\text { b) Mandiri berpikir } \\
\text { c) Meregulasi } \\
\text { kembali mental } \\
\text { yang dianggap } \\
\text { telah terganggu } \\
\text { setelah mengalami } \\
\text { pelbagai } \\
\text { permasalahan di }\end{array}$ \\
\hline
\end{tabular}




\begin{tabular}{|c|c|c|c|c|c|c|}
\hline & & & & & & $\begin{array}{l}\text { masa kanak-kanak } \\
\text { d) } \text { ODKA tidak } \\
\text { terlalu lama di } \\
\text { rumahsakit }\end{array}$ \\
\hline 5. & 2014 & $\begin{array}{l}\text { (Hagen, Woods- } \\
\text { Giscombe, Chung, \& } \\
\text { Beeber, 2014) }\end{array}$ & $\begin{array}{l}\text { Potential Benefits } \\
\text { of Dialectical } \\
\text { Behavioral Therapy } \\
\text { for Adolescents } \\
\text { Receiving } \\
\text { Treatment for } \\
\text { Borderline } \\
\text { Personality } \\
\text { Disorder Traits: } \\
\text { Implications for } \\
\text { Psychiatric Nurses }\end{array}$ & DBT & & $\begin{array}{l}\text { Gabungan terapi DBT } \\
\text { pada pasien rawat inap } \\
\text { dapat mengefektifkan } \\
\text { hasil, } \\
\text { Perawat yang sudah } \\
\text { memahami dan } \\
\text { menerima training DBT } \\
\text { dapat ikut berkontribusi } \\
\text { memberikan hasil yang } \\
\text { maksimal }\end{array}$ \\
\hline 6. & 2011 & (Quinn, 2011) & $\begin{array}{l}\text { A Person Center } \\
\text { Approach to the } \\
\text { Treatment of BPD }\end{array}$ & $\begin{array}{l}\text { System Training for } \\
\text { Emotional } \\
\text { Predictability an } \\
\text { Problem Solving } \\
\text { (STEPPS) }\end{array}$ & $\begin{array}{l}20 \text { minggu } \\
2 \text { jam tiap } \\
\text { pertemuan } \\
\text { Ada sesi } \\
\text { individu dan } \\
\text { sesi } \\
\text { kelompok }\end{array}$ & $\begin{array}{l}\text { Efektif dan efisien } \\
\text { karena ODKA diminta } \\
\text { WASPADA dengan } \\
\text { tanda-tanda KA } \\
\text { 1.Awareness of Illness : } \\
\text { ODKA diberi daftar } \\
\text { DSM ttg Ambang } \\
\text { 2.Emotion Management }\end{array}$ \\
\hline
\end{tabular}




\begin{tabular}{|c|c|c|c|c|c|}
\hline & & & & & $\begin{array}{l}\text { Skills Training } \\
\text { 3.Prediksi terjadinya } \\
\text { peristiwa pemicu KA } \\
\text { 4.Antisipasi } \\
\text { 5. Membangun percaya } \\
\text { diri } \\
\text { 6. Behavior Management } \\
\text { Skills Training }\end{array}$ \\
\hline 7. & 2010 & (Oldham, et al., 2010) & $\begin{array}{l}\text { Practice Guideline } \\
\text { for Treatmen of } \\
\text { Patiens with } \\
\text { Borderline } \\
\text { Personality } \\
\text { Disorder }\end{array}$ & $\begin{array}{l}\text { 1.Farmakoterapi } \\
\text { 2.DBT } \\
\text { 3. Psikodinamilk } \\
\text { 4. CBT }\end{array}$ & $\begin{array}{l}\text { Terapi menyeluruh dari } \\
\text { sekelompok terapis } \\
\text { dengan berbagai } \\
\text { pendekatan akan sangat } \\
\text { efektif }\end{array}$ \\
\hline 8. & 2009 & $\begin{array}{l}\text { Cottraux, } \\
\text { J.,Note,I.,Boutitie }\end{array}$ & $\begin{array}{l}\text { Cognitive therapy } \\
\text { versusRogerian } \\
\text { Supportive Therapy } \\
\text { in Borderline } \\
\text { Personality } \\
\text { Disorder }\end{array}$ & & $\begin{array}{l}\text { Pada terapi kognitif } \\
\text { ODKA lebih bertahan } \\
\text { dan tidak bosan } \\
\text { mengikuti intervensi. } \\
\text { Hal ini karena waktunya } \\
\text { tidak terlalu lama } \\
\text { Sangat efektif untuk } \\
\text { meningkatkan harapan } \\
\text { dan menurunkan } \\
\text { impulsif }\end{array}$ \\
\hline 9. & 2008 & Bellino et al & $\begin{array}{l}\text { Pharmacotherapy } \\
\text { for BPD }\end{array}$ & Pharmacotherapy & $\begin{array}{l}\text { Beberapa obat berhasil } \\
\text { menurunkan impusivitas }\end{array}$ \\
\hline
\end{tabular}




\begin{tabular}{|c|c|c|c|c|c|c|}
\hline & & & & & & suasana hati dan depresi \\
\hline 10. & 2008 & $\begin{array}{l}\text { (Kernberg, Yeomans, } \\
\text { Clarkin, \& Levy, } \\
\text { 2008) }\end{array}$ & $\begin{array}{l}\text { TFP: Overview and } \\
\text { Update }\end{array}$ & TFP & & \\
\hline $11 .$. & 2008 & $\begin{array}{l}\text { Zanarini,Mary C., } \\
\text { Frankenburg, }\end{array}$ & & Psikoedukasi & & $\begin{array}{l}\text { Menurunkan } \\
\text { impulsivitas namun } \\
\text { belum meningkatkan } \\
\text { kemampuan psikososial }\end{array}$ \\
\hline 12. & 2007 & $\begin{array}{l}\text { (Andri \& } \\
\text { Kusumawardhani, } \\
\text { 2007) }\end{array}$ & $\begin{array}{l}\text { Neurobiologi } \\
\text { Gangguan } \\
\text { Kepribadian } \\
\text { Ambang }\end{array}$ & Psikofarmakologi & & $\begin{array}{l}\text { Obatgolongan SSRI } \\
\text { mengurangi suara-suara } \\
\text { afektif }\end{array}$ \\
\hline 13. & 2007 & $\begin{array}{l}\text { (Fonagy \& Bateman, } \\
\text { 2007) }\end{array}$ & $\begin{array}{l}\text { Mentalizing and } \\
\text { BPD }\end{array}$ & MBT & & \\
\hline 14. & 2007 & $\begin{array}{l}\text { (Clarkin, Levy, } \\
\text { Lenzenweger, \& } \\
\text { Kernberg, 2007) }\end{array}$ & $\begin{array}{l}\text { Evaluating Three } \\
\text { Treatments for BPD }\end{array}$ & $\begin{array}{l}\text { 1.TFP } \\
\text { 2. DBT } \\
\text { 3. Supportive } \\
\text { Treatmen }\end{array}$ & & $\begin{array}{l}\text { a) Tahun pertama antara } \\
\text { TFP dan DBT sama- } \\
\text { sama efektif } \\
\text { mengurangi } \\
\text { keinginan bunuh diri } \\
\\
\text { b) TFP dan Suportif } \\
\text { mengurangi marah } \\
\text { yang impulsif } \\
\text { c) Selanjutnya TFP : } \\
\text { paling berperan } \\
\end{array}$ \\
\hline 15. & 2007 & (Hoffman, Fruzzetti, & Understanding and & Family Connections & 12 minggu & a. Ditemukan \\
\hline
\end{tabular}




\begin{tabular}{|c|c|c|c|c|c|c|}
\hline & & \& Buteau, 2007) & $\begin{array}{l}\text { engaging families: } \\
\text { An Education, } \\
\text { Skills and Support } \\
\text { Program for } \\
\text { relatives impacted } \\
\text { by Borderline } \\
\text { Personality } \\
\text { Disorder }\end{array}$ & Program & & $\begin{array}{l}\text { perkembangan signifikan } \\
\text { pada well-being } \\
\text { partisipan } \\
\text { b. Pengurangan terhadap } \\
\text { depresi secara signifikan } \\
\text { c. Wanita lebih tinggi } \\
\text { mengalami kegagalan } \\
\text { dibanding pria }\end{array}$ \\
\hline 16. & 2007 & $\begin{array}{l}\text { (Presius, Kaver, } \\
\text { Ekdahl, Asberg, \& } \\
\text { Samuelsson, 2007) }\end{array}$ & $\begin{array}{l}\text { Stress and burnout } \\
\text { in psychiatric } \\
\text { professionals when } \\
\text { starting to use } \\
\text { dialectical } \\
\text { behavioural therapy } \\
\text { in the work with } \\
\text { young self-harming } \\
\text { women showing } \\
\text { borderline } \\
\text { personality } \\
\text { symptoms }\end{array}$ & DBT & 18 bulan & $\begin{array}{l}\text { DBT adalah terapi yang } \\
\text { mungkin membuat stress } \\
\text { untuk dipelajari, namun } \\
\text { berguna karena struktur } \\
\text { ilmiahnya, bentuk } \\
\text { teamwork, dan adanya } \\
\text { pengawasan yang sering, } \\
\text { Sedangkan mindfulness } \\
\text { dapat mengurangi stress }\end{array}$ \\
\hline 17. & 2006 & $\begin{array}{l}\text { (Brown \& Shapiro, } \\
\text { 2006) }\end{array}$ & $\begin{array}{l}\text { EMDR in the } \\
\text { treatment of BPD }\end{array}$ & EMDR & & $\begin{array}{l}\text { Berguna untuk } \\
\text { mengurangiTrauma } \\
\text { Masa Anak }\end{array}$ \\
\hline 18. & 2006 & $\begin{array}{l}\text { (Kellogg \& Young, } \\
\text { 2006) }\end{array}$ & $\begin{array}{l}\text { Schema Therapy for } \\
\text { Borderline } \\
\text { Personality }\end{array}$ & $\begin{array}{l}\text { Schema- Focused } \\
\text { Therapy }\end{array}$ & $\begin{array}{l}\text { tahap: } \\
\text { 1.Limited } \\
\text { 2.Reparenti }\end{array}$ & $\begin{array}{l}\text { Mengembangkan pola } \\
\text { hidup kesehatan dewasa, } \\
\text { memperoleh kestabilan }\end{array}$ \\
\hline
\end{tabular}




\begin{tabular}{|c|c|c|c|c|c|c|}
\hline & & & Disorder & & $\begin{array}{l}\text { ng } \\
\text { 3.Emotion- } \\
\text { Focused } \\
\text { Work } \\
\text { Cognitive } \\
\text { restructuring } \\
\text { and } \\
\text { education } \\
\text { 4.Behaviora } \\
1 \text { pattern } \\
\text { breaking }\end{array}$ & $\begin{array}{l}\text { emosi, tujuan ynag } \\
\text { terarah pada perilaku, } \\
\text { hubungan yang saling } \\
\text { meneguhkan, } \\
\text { kesejahteraan umum }\end{array}$ \\
\hline 19. & 2006 & $\begin{array}{l}\text { (Levy, Meehan, Kelly, } \\
\text { Clarkin, Kernberg, \& } \\
\text { Weber, 2006) }\end{array}$ & $\begin{array}{l}\text { Change in } \\
\text { Attachment Pattern } \\
\text { and reflective } \\
\text { Function in a } \\
\text { Randomized } \\
\text { Control Trial of } \\
\text { TFP for BPD }\end{array}$ & $\begin{array}{l}\text { 1.TFP } \\
\text { 2. DBT } \\
\text { 3. Supportive } \\
\text { Treatmen }\end{array}$ & & \\
\hline 20. & 2006 & $\begin{array}{l}\text { (Levy, Clarkin, } \\
\text { Yeomans, Scott, } \\
\text { Wasserman, \& } \\
\text { Kernberg, 2006) }\end{array}$ & $\begin{array}{l}\text { The Mechanisms of } \\
\text { Change in the } \\
\text { Treatment of BPD } \\
\text { with Transference }\end{array}$ & TFP & & $\begin{array}{l}\text { Dapat menurunkan } \\
\text { keinginan bunuh diri, } \\
\text { kemarahan, kecemasan } \\
\text { dan meningkatkan }\end{array}$ \\
\hline
\end{tabular}




\begin{tabular}{|c|c|c|c|c|c|c|}
\hline & & & $\begin{array}{l}\text { Focus } \\
\text { Psychotherapy } \\
\text { (TFP) }\end{array}$ & & & $\begin{array}{l}\text { penyesuaian sosial } \\
\text { (dibanding terapi } \\
\text { suportif) }\end{array}$ \\
\hline 21 & 2003 & $\begin{array}{l}\text { Leichsenring and } \\
\text { Leibing }\end{array}$ & $\begin{array}{l}\text { The Effectiveness } \\
\text { of Psychodinamic } \\
\text { Therapy and CBT } \\
\text { in Borderline } \\
\text { Personality }\end{array}$ & & & $\begin{array}{l}\text { CBT cocok untuk terapi } \\
\text { sosial dan interpersonal. } \\
\text { Psikodinamik lebih baik } \\
\text { untuk mengurangi } \\
\text { depresi }\end{array}$ \\
\hline 22. & 2003 & $\begin{array}{l}\text { (Verheul, Van Den } \\
\text { Bosch, Koeter, De } \\
\text { Ridder, Stijnen, \& } \\
\text { Van Den Brink, 2003) }\end{array}$ & $\begin{array}{l}\text { Dialectical } \\
\text { Behavior Therapy } \\
\text { (DBT) for woman } \\
\text { with BPD }\end{array}$ & $\begin{array}{l}\text { DBT } \\
\text { Mindfulness } \\
\text { Regulasiemosi } \\
\text { Distress tolerance } \\
\text { Efektivitas } \\
\text { interpersonal }\end{array}$ & 12 bulan & $\begin{array}{l}\text { - } \begin{array}{l}\text { Mengurangi perilaku } \\
\text { beresiko }\end{array} \\
\text { - Pendekatan kognitif- } \\
\text { perilaku yang } \\
\text { menekankan aspek } \\
\text { psikososial dan } \\
\text { biososial } \\
\text { - Dukungan } \\
\text { - Kognitif bahwa org } \\
\text { tidak wajib sempurna } \\
\text { - Hubungan } \\
\text { interpersonal } \\
\text { - Belajar mengatur } \\
\text { emosi }\end{array}$ \\
\hline 23. & 2001 & $\begin{array}{l}\text { (McMain, Korman, \& } \\
\text { Dimeff, 2001) }\end{array}$ & $\begin{array}{l}\text { DBT and the } \\
\text { Treatment of }\end{array}$ & DBT & & \\
\hline
\end{tabular}




\begin{tabular}{|c|c|c|c|c|c|c|}
\hline & & & $\begin{array}{l}\text { Emotion } \\
\text { Dysregulation for } \\
\text { BPD }\end{array}$ & & & \\
\hline 24. & 1995 & Glick, Dulit & $\begin{array}{l}\text { The Family, Family } \\
\text { Therapy and BDP }\end{array}$ & Family Therapy & & $\begin{array}{l}\text { Terapi Borderline harus } \\
\text { seimbang antara terapi } \\
\text { obat dan terapi keluarga } \\
\text { supaya efektif }\end{array}$ \\
\hline 25. & 1994 & $\begin{array}{l}\text { (Miller, Eisner, \& } \\
\text { Allport, 1994) }\end{array}$ & $\begin{array}{l}\text { Creative Coping: A } \\
\text { Cognitive- } \\
\text { Behavioral Group } \\
\text { for Borderline } \\
\text { Personality Disorde }\end{array}$ & $\begin{array}{l}\text { Creative Coping } \\
\text { using Cognitive- } \\
\text { Behavioral } \\
\text { Framework }\end{array}$ & $\begin{array}{l}\text { Selama } 2 \\
\text { minggu, per } \\
\text { sesi } 45 \text { menit } \\
\text { a.Modul 1. } \\
\text { Emotional } \\
\text { Control and } \\
\text { Regulation (5 } \\
\text { sesi) } \\
\text { b.Modul 2. } \\
\text { Interpersonal } \\
\text { Effectiveness } \\
\text { (4 sesi) } \\
\text { c.Distress } \\
\text { Tolerance }\end{array}$ & $\begin{array}{l}\text { Ada hasil positif, } \\
\text { Creative Coping Group } \\
\text { menyediakan insight } \\
\text { bagi pasien }\end{array}$ \\
\hline
\end{tabular}




\begin{tabular}{|c|c|c|c|c|c|}
\hline 26. & 1991 & (Westen, 1991) & $\begin{array}{l}\text { Cognitive- } \\
\text { behavioral } \\
\text { intervention in the } \\
\text { Psychoanalitic } \\
\text { psychotherapy of } \\
\text { Borderline } \\
\text { personalitydiorder }\end{array}$ & $\begin{array}{l}\text { Cognitive behavioral } \\
\text { interventions }\end{array}$ & $\begin{array}{l}\text { Berguna dalam } \\
\text { menargetkan regulasi diri } \\
\text { dan proses sosial. } \\
\text { Pendekatan kognitif } \\
\text { digabung dengan } \\
\text { psikodinamis }\end{array}$ \\
\hline
\end{tabular}




\section{DAFTAR PUSTAKA}

Andri, \& Kusumawardhani, A. (2007). Neurobiologi Gangguan Kepribadian Ambang: Pendekatan Biologis Perilaku Impulsif dan Agresif. Maj Kedokt Indon , 57, 124-128.

Brown, S., \& Shapiro, F. (2006). EMDR in the Treatment of Borderline Personality Disorder. Clinical Case Studies , 5, 403-420.

Chafos, V. H., \& Economou, P. (2014). Beyond Borderline Personality Disorder: The Mindful Brain. Social Work, 59, 297-302.

Clarkin, J. F., Levy, K. N., Lenzenweger, M. F., \& Kernberg, O. F. (2007). Evaluating Three Treatments for Borderline Personality Disorder: A Multiwave Study. Am $\boldsymbol{J}$ Psychiatry, 164, 922-928.

Eijk, C. V. (2014). Meta-Analysis of Mentalization Based Treatment (MBT) and Schema Focused Therapy for Borderline Personality Disorder: What Works for Whom? Meta-Analysis Borderline Personality Disorder , 1-23.

Fonagy, P., \& Bateman, A. W. (2007). Mentalizing and Borderline Personality Disorder. Journal of Mental Health , 16, 83101.
Hagen, S., Woods-Giscombe, C. L., Chung, J., \& Beeber, L. S. (2014). Potential Benefits of Dialectical Behavioral Therapy for Adolescents Receiving Treatment for Borderline Personality Disorder Traits: Implications for Psychiatric Nurses. Nursing and Health , 2, 89-99.

Hoffman, P. D., Fruzzetti, A. E., \& Buteau, E. (2007). Understanding and engaging families: An Education, Skills and Support Program for relatives impacted by Borderline Personality Disorder. Journal of Mental Health, 16, 69-82.

Kellog, S., \& Young, J. (2006). Schema Therapy for Borderline Personality Disorder. Journal of Clinical Psychology , 62, 445-458.

Kellogg, S. H., \& Young, J. E. (2006). Schema Therapy for Borderline Personality Disorder. Journal of Clinical Psychology , 62, 445-458.

Kernberg, O. F., Yeomans, F. E., Clarkin, J. F., \& Levy, K. N. (2008). Transference Focused Psychotherapy: Overview and Update. Int J Psychoanal , 89, 601620.

Levy, K. N., Clarkin, J. F., Yeomans, F. E., Scott, L. 
N., Wasserman, R. H., \& Kernberg, O. F. (2006). The Mechanism of Change in the Treatment of Borderline Personality Disorder with Transference Focused Therapy. Journal of Clinical Psychology, 62, 481-501.

Levy, K. N., Meehan, K. B., Kelly, K. M., Clarkin, J. F., Kernberg, O. F., \& Weber, M. (2006, September 18). Change in Attachment Patterns and Reflective Function in a Randomized Control Trial of Transference-Focused Psychotherapy for Borderline Personality Disorder. Journal of Consulting and Clinical Psychology, 1027-1040.

McMain, S., Korman, L. M., \& Dimeff, L. (2001). Dialectical Behavior Therapy and The Treatment of Emotion Dysregulation. In Session: Psychoterapy in Practice, 57, 183-196.

Miller, C. R., Eisner, W., \& Allport, C. (1994). Creative Coping: A Cognitive-Behavioral

Group for Borderline Personality Disorde. Archives of Psychiatric Nursing, VIII, 280-285.

Oldham, J. M., Gabbard, G. O., Goin, M. K., Gunderson, J., Soloff, P., Spiegel, D., et al. (2010). Practice
Guideline for Treatmen of Patiens with Borderline Personality Disorder. APA Practice Guidelines , 1-55. Presius, K.-I., Kaver, A., Ekdahl, S., Asberg, M., \& Samuelsson, M. (2007). Stress and burnout in psychiatric professionals starting to use dialectical behavioural therapy on young self-harming women showing borderline personality symptoms. Journal of Psychiatric and Mental Health Nursing, 14, 635-643.

Quinn, A. (2011). A Person Center Approach to the Treatment of Borderline Personality Disorder. Journal of Humanistic Psychology, 51, 465.

Verheul, R., Van Den Bosch, L. M., Koeter, M. W., De Ridder, M. A., Stijnen, T., \& Van Den Brink, W. (2003). Dialectical Behaviour Therapy for Women with Borderline Personality Disorder. British Journal of Psychiatry, 182, 135-140.

Westen, D. (1991). Cognitivebehavioral interventions in the psychoanalytic psychotherapy of borderline personality disorders. Clinical Psychology Review , 11, 211-230.

Zavala, S. S., Bentley, K. H., \& Wilner, J. G. (2015). 
Transdiagnostic Treatment of Borderline Personality Disorder and Comorbid Disorders: A Clinical Replication Series. Journal of Psychology Disorders, 29, 1-17. 